\title{
Relação entre o Fator de Crescimento Endotelial Vascular Tumoral e o CA 125 Plasmático em Pacientes com Neoplasias Epiteliais do Ovário
}

Autor: Francisco José Candido dos Reis

Orientador: Prof. Dr. Jurandyr Moreira de Andrade

Tese de Doutorado apresentada à Faculdade de Medicina de Ribeirão Preto da Universidade de São Paulo - Área de concentração: Tocoginecologia, em 20/04/99.

Objetivos: Verificar a relação entre a concentração plasmática de CA 125, nas pacientes com neoplasias epiteliais benignas e malignas do ovário, e a capacidade do tumor induzir angiogênese e permeabilidade vascular pela produção de VEGF (Fator de Crescimento Endotelial Vascular).

Pacientes e Métodos: Foram incluídas no estudo 50 pacientes com neoplasia epitelial cística do ovário, 10 cistadenocarcinomas (7 invasores e 3 borderline) e 40 cistadenomas (15 mucinosos e 25 serosos). Determinouse os niveis plasmático e intratumoral de CA 125 por Quimioluminescência e de VEGF por ELISA.

Resultados: Não encontramos correlação entre os níveis plasmático e intratumoral de CA $125(\mathrm{r}=0,07 ; \mathrm{p}=0,61)$, entre o nivel plasmático e o CA 125 total intra-tumoral $(\mathrm{r}=0,26 ; \mathrm{p}=0,06)$ ou entre o nivel plasmático de CA 125 e de VEGF $(\mathrm{r}=0,19 ; \mathrm{p}=0,18)$. A produção tumoral de VEGF, contudo correlacionou-se de forma estatisticamente significante com o nivel plasmáticos de $\mathrm{CA}$ 125 , tanto por sua concentração $(r=0,44 ; p=0,0015)$ quanto por sua quantidade total intratumoral $(\mathrm{r}=0,53$; $\mathrm{p}<0,0001)$.

Conclusões: O nível circulante do CA 125 não é relação direta de sua produção pelo tumor, correlaciona-se com a capacidade do tumor induzir angiogênese e aumento da permeabilidade vascular através da sintese de VEGF.

Palavras-chave: Câncer de ovário. CA 125. Angiogênese.

\section{Avaliação da Imunoexpressão do Anticorpo Monoclonal MIB-1 no Epitélio Mamário Adjacente ao Fibroadenoma de Mulheres no Menacme Tratadas com Tamoxifeno}

Autor: Juarez Antônio de Sousa

Orientador: Prof. Dr. Luiz Henrique Gebrim

Tese de Mestrado apresentada à Universidade Federal de São Paulo - Escola Paulista de Medicina em 08/04/99

A quimioprofilaxia do câncer mamário com tamoxifeno tem reduzido em $45 \%$ a incidência de câncer em mulheres de alto risco, segundo dados do "National Cancer Institute" (1998). Seus efeitos sobre o tecido mamário normal são pouco conhecidos, bem como sua interação com os receptores esteróides e a dose-efeito. Estudou-se por técnica imuno-histoquímica, através da imunoexpressão do anticorpo monoclonal MIB-1 (IMUNOTECH, catálogo $\mathrm{n}^{\circ}$ 0505, lote 001), a atividade proliferativa no epitélio mamário adjacente ao fibroadenoma de 44 pacientes, de forma aleatória em duplo-cego, divididas em 3 grupos: $\mathrm{A}(\mathrm{N}=16$; placebo), $\mathrm{B}$ $(\mathrm{N}=15$; tamoxifeno, $10 \mathrm{mg})$ e $\mathrm{C}(\mathrm{N}=13$; tamoxifeno, 20 $\mathrm{mg}$ ). O medicamento foi utilizado por 22 dias, a partir do $2^{\circ}$ dia do ciclo menstrual, sendo a cirurgia realizada no $23^{\circ}$ dia. O perfil hormonal foi analisado pela dosagem sérica de estradiol, progesterona, SHBG (globulina transportadora de hormônios esteróides), FSH (hormônio folículo-estimulante), LH (hormônio luteinizante) e prolactina, entre os dias 21 e 24 do ciclo menstrual prévio, e no dia da cirurgia. Os grupos B e C apresentaram aumento significante nos niveis de progesterona $(p=0,038)$, estradiol $(p<0,001)$ e SHBG $(p=0,001)$. No grupo $C$, observou-se elevação na concentração sérica de FSH $(p=0,0045)$ e queda dos niveis de prolactina $(\mathrm{p}=0,0055)$. A porcentagem média de núcleos corados por 1000 células no grupo A foi 9,2; no grupo B, 4,5; e no grupo C, 3,2. O teste de Fisher revelou que o tamoxifeno reduziu de forma significante a imunoexpressão do MIB-1 nas doses de 10 e $20 \mathrm{mg}$ em comparação com o grupo placebo $(p<0,0001)$ e não houve variação significante da atividade proliferativa nas doses de 10 e $20 \mathrm{mg}$ de tamoxifeno $(\mathrm{p}=0,21)$. Conclui-se que o tamoxifeno reduziu de forma significante a atividade proliferativa do epitélio mamário, nas doses de 10 e 20 mg/dia.

Palavras-chave: Mama normal. Tamoxifeno. Fibroadenoma. 